\title{
Stereoacuity Among Patients with Refractive Error at University of Gondar, Northwest Ethiopia
}

\author{
Mikias Mered Tilahun (D) \\ Mohammed Seid Hussen \\ Getasew Alemu Mersha \\ Biruk Lelisa Eticha \\ Department of Optometry, School of \\ Medicine, University of Gondar, \\ Comprehensive Specialized Hospital, \\ Gondar, Ethiopia
}

Purpose: This study aimed to assess the level of stereopsis, proportion of poor stereopsis, and factors influencing stereopsis in adults with refractive error.

Methods: This was a cross-sectional, descriptive study conducted on 153 adults with refractive error at Gondar University Hospital Tertiary Eye Care Center from April 08 to June 07, 2019. Structured questionnaires and ophthalmic instruments (Retinoscope, Worth Four Dot test and TNO Stereo plates) were used to collect the data. Data were entered and analyzed with Statistical Package for Social Sciences (SPSS) version 20. The result was summarized using summary statistics such as mean. Chi-squared test of association was applied between stereopsis and independent variables.

Results: The level of stereopsis after correction of refractive error ranged from 1.89 to 2.65 $\log$ arc second. Before correction of refractive error, poor stereopsis was observed in $46.4 \%$ of the participants, while after correction, it dropped to $39.8 \%$ (CI: $95 \%$ : $31.1 \%-47.8 \%$ ). Stereopsis after correction had a significant association with age, best visual acuity, type of refractive error, and fusional status at distance with a $\mathrm{p}$ value $<0.05$.

Conclusion: Given refractive error corrected, the mean stereopsis in patients with refractive error was $2.42 \mathrm{log}$ arc second. Proportion of poor stereopsis was noted in $39.8 \%$ of the participants corrected for refractive error. Age, best corrected visual acuity, type of refractive error, and fusional status had a significant association with stereopsis. Further studies on stereoacuity on a large scale are recommended.

Keywords: stereoacuity, poor stereoacuity, refractive error, Gondar, Ethiopia

\section{Introduction}

Stereopsis has been defined as the perception of depth via binocular analysis of the three-dimensional structure of objects. Threshold stereoacuity refers to the smallest angle of binocular disparity (measured in arc seconds) that can provoke perception of depth or stereopsis. ${ }^{1,2}$

Globally, the assessment of stereoacuity among patients with refractive error has been mainly limited to children and young adults. The level of stereoacuity was $50.2 \pm 50.6 \mathrm{sec}$ arc in East China ${ }^{7}$ among myopic children, 120.60 \pm 76.36 seconds of arc in North India ${ }^{8}$ among all refractive cases, 120 seconds of arc in the United States of America ${ }^{4}$ in hyperopic children, $133 \pm 68.6$ seconds of arc in Iran $^{9}$ among young adults, and $130 \pm 30$ seconds of arc in Deagu ${ }^{5}$ among children and adults.

Poor stereoacuity has been linked with poor quality of vision and poor work performance especially in tasks which need eye-hand coordination and visual motor skills. Subsequently, poor quality of vision due to lack of stereopsis in an individual leads to reduction in work productivity and quality of life. ${ }^{3}$
Correspondence: Getasew Alemu Mersha POB: 196

Tel +251932823935

Fax +25I-058-II4 1240

Email gechopta12@gmail.com (c) $(7) 2021$ Tilahun et al. This work is published and licensed by Dove Medical Press Limited. The full terms of this license are available at https://www.dovepress.com/terms. (c) ${ }_{\mathrm{BY}} \mathrm{NC}$ php and incorporate the Creative Commons Attribution - Non Commercial (unported, v3.0) License (http://creativecommons.org/licenses/by-nc/3.0/). By accessing the work you hereby accept the Terms. Non-commercial uses of the work are permitted without any further permission from Dove Medical Press Limited, provided the work is properly attributed. For permission for commercial use of this work, please see paragraphs 4.2 and 5 of our Terms (https://www.dovepress.com/terms.php). 
Stereopsis in adults is affected by socio-demographic variables, ocular and optical factors such as, level of best corrected visual acuity, inter eye difference in best corrected visual acuity, type and degree of refractive error, intraocular difference in cylindrical refractive error and spherical power, type and degree of anisometropia, and pupillary distance. ${ }^{4-18}$ Stereopsis could be improved through early correction of refractive error, surgery for "eye turn", and maintaining binocular vision.

Despite the huge influence of stereopsis on day to day activities and work performance in adults, it is poorly understood for its magnitude and possible related factors once refractive error has been corrected with glasses. The result of the study will be used as base line data on stereoacuity of adult population with refractive error and used for a better provision of services rendered to these groups.

Moreover, no estimate was found on stereopsis in our country, Ethiopia, in general and the study area in particular. Therefore this study desired to assess the level of stereoacuity, magnitude of poor stereopsis, and associated factors in adults with refractive error at University of Gondar Tertiary Eye Care and Training Center, Northwest Ethiopia.

\section{Methods and Materials}

The University of Gondar Tertiary Eye Care and Training Center has been providing full eye examinations for patients with refractive and binocular vision disorder in Gondar City and nearby areas in Northwest Ethiopia. Patients with squint, involuntary eye movement, cataract, glaucoma or any retinal disease were excluded from the study.

A total of 153 patients with refractive error were enrolled in the study after a careful sample size determination based on a single proportion formula and applying correction formula for the size of target population. Then, simple random sampling was used prospectively to examine level of stereopsis from April 08 to June 07, 2019. Data quality was ensured through training of the data collectors for about two days and pretesting the questionnaire on $5 \%$ of the sample. Ethical clearance was obtained from ethical review committee of University of Gondar. After the objective of the study was described to participants, verbal informed consent was obtained from each participant and approved by the ethical review committee of the University of Gondar with a reference No S/N/1356/ 2011E.C. For participants aged below 18 years, oral informed consent was taken from their parents or legal guardians and assent from themselves. Generally, the study was conducted in accordance with the Declaration of the Principle of Helsinki.

\section{Data Collection Tool and Procedures}

Data was collected using structured questionnaires and ophthalmic equipment such as Snellen visual acuity chart, TNO stereo test, Red Green Goggle Frame and Worth Forth Dot test. Three optometrists were involved in the data collection process. Ocular health examination was performed by the optometrists in the outpatient department. Anterior segment examination was carried out with slit lamp biomicroscopy and posterior segment evaluation with $90 \mathrm{D}$ volk lens. Distance visual acuity was taken at distance of $6 \mathrm{~m}$ whereas near visual acuity was taken at $40 \mathrm{~cm}$ with appropriate near add power in place. Unilateral and alternating cover test were performed. Ocular motility was assessed with a pen torch at $33 \mathrm{~cm}$ distance. Dry static retinoscopy followed by monocular subjective refraction were performed at $6 \mathrm{~m}$ for all study participants. For those who had presbyopia, near refraction was performed.

Binocular fusional status of the participants was checked with Worth Four Dot test at $40 \mathrm{~cm}$ after the appropriate amount of distance and near prescription was determined. Stereopsis was measured with TNO stereo test (Lameris, Ootech Netherlands). Red-green anaglyph filters and appropriate near glass under the filters were worn when necessary.

All the examinations were performed with a standard background room illumination. The level of stereopsis was recorded as the highest level of stereopsis correctly identified. If a participant made one mistake and responded correctly on the next level of stereopsis, the missed one was tried again to ensure the subject really achieved that level of stereopsis instead of just guessing the more difficult one. The level of stereopsis was categorized as good stereoacuity $(<120 \mathrm{sec}$ arc), moderate stereoacuity (121-240 sec arc), and poor stereoacuity ( $>241 \mathrm{sec} \operatorname{arc}) .{ }^{4}$

\section{Data Processing and Analysis}

After the collected data was checked for completeness and consistency, data were entered into EPI info 7 and exported and analyzed by SPSS (version 20). After the data were analyzed, the result was summarized using summary statistics such as mean. The association between stereopsis and other categorical variables was assessed 
using Chi-squared test. Those variables with p-value of less than 0.05 were considered as having a statistically significant association. Finally, the finding was presented and organized in tabular and graphical form.

\section{Results}

The study consecutively enrolled 153 patients who had refractive error with a mean age of $40 \pm 17$ years. The majority of patients were male (66\%) and urban dwellers (65.4\%), had University /college level of education (38.6\%), and private jobs (35.3\%), (Table 1). Regarding the clinical variables, majority of the patients had good visual acuity (66\%), spherical ametropia (74\%), anisometropia (55\%), and normal binocular single vision (90\%), (Table 2). In this study, the level of stereopsis after correction ranged from $1.89 \mathrm{log}$ arc second to $2.65 \mathrm{log}$ arc second. The proportion of poor stereopsis before correction was 46.4\% (CI: 95\%:38.6-54.9) and after correction was 39.8\% (CI: 95\%: 31.1\%- 47.8\%), (Figure 1).

Table I Socio Demographic Characteristics of the Study Participants at University of Gondar Hospital Tertiary Eye Care and Training Center, Northwest Ethiopia, 202I $(n=153)$

\begin{tabular}{|l|l|l|}
\hline Variables & Frequency & Percent (\%) \\
\hline Age & & \\
I7-23 & 39 & 25.5 \\
$24-40$ & 40 & 26.1 \\
$41-52$ & 37 & 24.2 \\
$53-85$ & 37 & 24.2 \\
\hline Sex & & \\
Male & 101 & 66.0 \\
Female & 52 & 34.0 \\
\hline Residence & & \\
Urban & 100 & 65.4 \\
Rural & 53 & 34.6 \\
\hline Educational Status & & \\
Cannot read and write & 38 & 24.8 \\
Can read and write & 21 & 13.7 \\
Primary school & 9 & 5.9 \\
Secondary school & 26 & 17.0 \\
University/College & 59 & 38.6 \\
\hline Occupation & & \\
Private & 54 & 35.3 \\
Student & 43 & 28.1 \\
Governmental & 28 & 16.3 \\
Housewife & 25 & \\
Retired & 3 & \\
\hline
\end{tabular}

Table 2 Clinical Characteristics of the Participants at University of Gondar Hospital Tertiary Eye Care and Training Center, Northwest Ethiopia, 202I $(n=\mid 53)$

\begin{tabular}{|l|l|l|}
\hline Variables & Frequency & Percent (\%) \\
\hline BCVA & & \\
$6 / 6-6 / 18$ & 101 & 66 \\
$6 / 24-6 / 60$ & 34 & 22.2 \\
$<6 / 60$ & 18 & 11.8 \\
\hline Inter-eye difference in BCVA & & \\
No line difference & 91 & 59.7 \\
I-2 line difference & 47 & 30.7 \\
3-4 line difference & 15 & 9.8 \\
\hline Pupillary distance & & \\
<62mm & 37 & 24.2 \\
62-66mm & 107 & 69.9 \\
$>$ 66mm & 9 & 5.9 \\
\hline Type of Refractive error & & \\
Hyperopia & 61 & 39.9 \\
Myopia & 52 & 34 \\
Astigmatism & 40 & 26.1 \\
\hline Binocular optical status & & \\
Anisometropia & 84 & 54.9 \\
Isometropia & 69 & 45.1 \\
\hline Degree of anisometropia & & \\
0-2.00DS & 143 & 9.5 \\
>2.00DS & 10 & \\
\hline Fusional status & 158 & \\
Normal & & \\
Abnormal & & \\
\hline
\end{tabular}

On applying a Chi-squared test, stereopsis after correction of refractive error had significant association with age, best corrected visual acuity, inter-eye difference in visual acuity, type of refractive error, and fusional status. However binocular optical status had no significant association with stereopsis after correction (Table 3).

\section{Discussion}

Extensive literature search did not reveal even a single estimate on stereopsis among patients with refractive error in Ethiopia; this is the first estimate on the level stereopsis and proportion of poor stereopsis in patients with refractive error. The proportion of poor stereopsis after correction was found to be $39.8 \%$ (CI: 95\%: $31.1 \%$ - 47.8\%) higher than the study done in East China $^{7}(0.2 \%)$.This discrepancy might be due to the difference in target population and study setting. After 


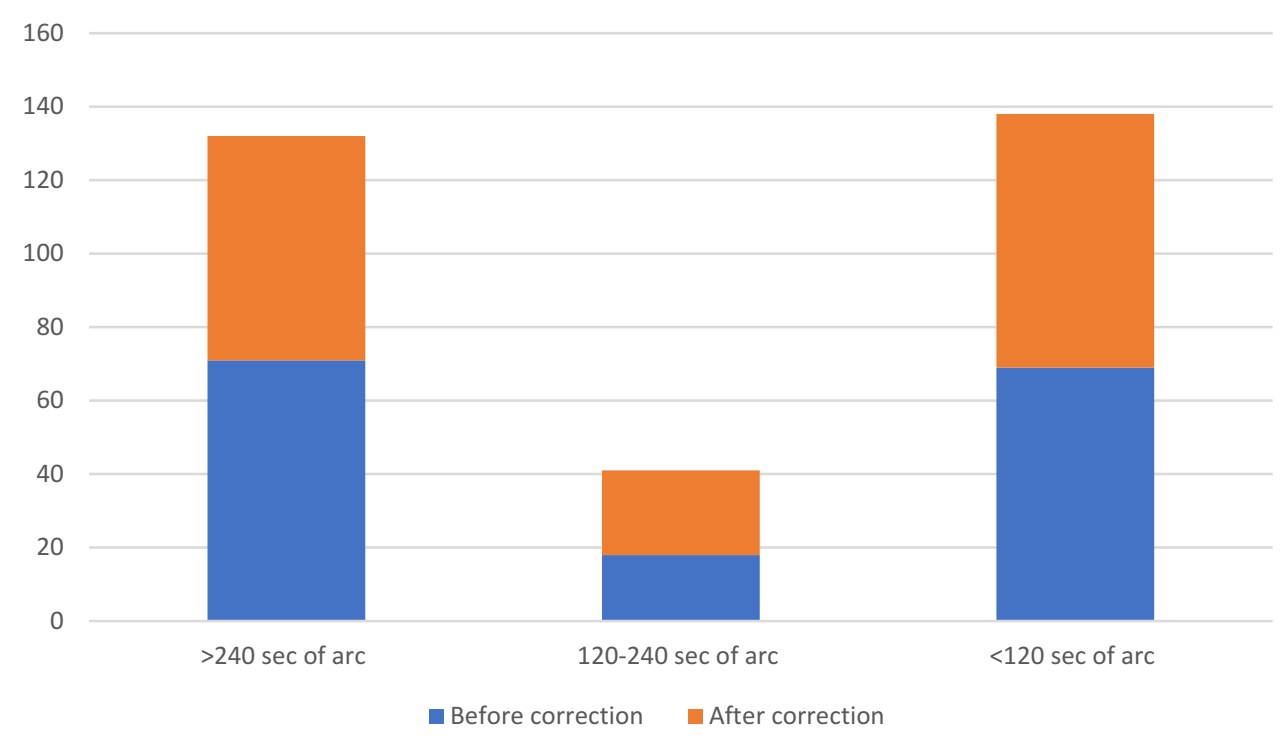

Figure I Participants' stereopsis before and after correction at Gondar University Hospital tertiary eye care and training center, Northwest Ethiopia, 202I ( $\mathrm{n}=\mathbf{1 5 3}$ ).

correction of refractive error the number of patients with poor stereopsis was dropped just by $6.6 \%$ compared to before correction and this could be because adult patients who had had abnormal binocular interaction or long standing amblyopia would remain on the level of poor stereopsis even if refractive error was addressed.

The mean stereopsis after correction ranged from 1.89 $\log$ arc second to $2.65 \mathrm{log}$ arc second, lower compared to studies done in East china ${ }^{7}$ on myopic patients (50.2 \pm $50.6 \mathrm{sec}$ arc), North India $^{8}$ on all refractive cases $(120.60$ \pm 76.36 seconds of arc), United States of America ${ }^{4}$ on hyperopic patients (120 seconds of arc), $\operatorname{Iran}^{9}(133 \pm 68.6$ seconds of arc) and Deagu ${ }^{5}(130 \pm 30$ seconds of arc). The observed difference might be due to the specificity of these studies in terms of age group, refractive error and binocular vision anomalies of participants. Besides, these studies utilized a Titmus stereo test plates against a TNO test plates in the current study. Titmus stereo test plate over estimates the stereoacuity level due to its monocular clue. Furthermore, in Titmus test the process of form recognition happens prior to the fusion of the targets and eventually perception of depth however, in TNO test the fusion of targets happen first prior to recognition of form and perception of depth. ${ }^{24}$

Another interesting finding in this study was patients who had a visual acuity of below $6 / 60$ had obtained relatively a better stereoacuity with less than $120 \mathrm{sec}$ arc this might be probably due to the difference in patients' understanding, cooperativeness and nature of the test.
Regarding the factors related to stereopsis; age, best corrected visual acuity, types of refractive error and fusional status had significant association with stereopsis after correction. Stereopsis was influenced through age of participants and this is consistent with Japan, ${ }^{19}$ United States of America $^{20}$ reported that age had a significant influence on stereoacuity. The precise mechanism by which stereopsis influenced through age is unknown. ${ }^{21,22}$ Best corrected visual acuity had significant association with stereopsis, which is supported by the studies done in Switzerland, ${ }^{18}$ United States of America ${ }^{4}$ and Peru, ${ }^{23}$ which revealed that, poor best corrected visual acuity had a significant influence on stereopsis. Individuals with poor visual acuity might have a chance to be amblyopic, which leads to limited fusional status. ${ }^{4,23}$

On the other hand, fusional status had significant association with stereopsis. This finding is in agreement with the studies done in Switzerland, ${ }^{18}$ and United States of America, ${ }^{4}$ which concluded that, stereopsis was significantly reduced in patients with poor fusional status. Poor fusional status degrades vision in one eye through blurring; filtering or reducing contrast here by it diminishes stereoacuity. ${ }^{4}$

Furthermore, type of refractive error was related with stereopsis and this was in line with studies done in East China,${ }^{7}$ India, ${ }^{8}$ United States of America, ${ }^{4}$ Taiwan ${ }^{13}$ and Australia. ${ }^{12}$ Refractive errors reduce binocular function through inducing visual blur and impairing the sensory fusion which eventually leads poor stereopsis. ${ }^{7}$ 
Table 3 Chi-Squared Test Showing Association Between Stereopsis After Correction and Clinical Related Variables at Gondar University Hospital Tertiary Eye Care and Training Center, Northwest Ethiopia, 202I ( $n=153)$

\begin{tabular}{|c|c|c|c|c|c|}
\hline \multirow[t]{2}{*}{ Variable } & \multicolumn{3}{|c|}{ Stereopsis After Correction } & \multirow[t]{2}{*}{$P$ value } & \multirow[t]{2}{*}{$x^{2}$ - Value } \\
\hline & $<120$ secarc & $12 \mid-240 \mathrm{sec}$ arc & $24 I-480 \mathrm{sec}$ arc & & \\
\hline Age & & & & $<0.001$ & 42.822 \\
\hline $17-23$ & 26 & 4 & 9 & & \\
\hline $24-40$ & 25 & 2 & 13 & & \\
\hline $4 I-52$ & 15 & 11 & 11 & & \\
\hline $53-85$ & 3 & 6 & 28 & & \\
\hline BCVA & & & & $<0.001$ & 27.082 \\
\hline $6 / 6-6 / 18$ & 54 & 14 & 1 & & \\
\hline $6 / 18-6 / 60$ & 17 & 6 & 0 & & \\
\hline$<6 / 60$ & 30 & 14 & 17 & & \\
\hline Type of refractive error & & & & 0.019 & 11.748 \\
\hline Hyperopia & 8 & 28 & 25 & & \\
\hline Myopia & 19 & II & 22 & & \\
\hline Astigmatism & 10 & 16 & 14 & & \\
\hline Fusional status & & & & $<0.001$ & 19.870 \\
\hline Normal & 68 & 23 & 47 & & \\
\hline Abnormal & 1 & 0 & 14 & & \\
\hline Inter eye visual acuity difference & & & & 0.0110 & 7.535 \\
\hline No line difference & 27 & 33 & 31 & & \\
\hline I-2-line difference & 9 & 14 & 24 & & \\
\hline 3-4-line difference & 1 & 8 & 6 & & \\
\hline Binocular optical status & & & & 0.057 & 5.744 \\
\hline Anisometropia & 14 & 33 & 37 & & \\
\hline Isometropia & 23 & 22 & 24 & & \\
\hline
\end{tabular}

Note: Level of significance, $\mathrm{p}<0.05$.

\section{Limitation of the Study}

The study was conducted relatively on a few numbers of patients with refractive error that did not allow us to infer the result for population with refractive error. Cross sectional nature of the study and failure to incorporate strong analysis like binary and multiple logistic regressions to find out important predictors of poor stereopsis were identified as limitations in this study.

\section{Conclusion}

The proportion of poor stereopsis after correction was 39.8\% (CI: 95\%: 31.1\%- 47.8\%) and the mean stereopsis after correction of refractive error was $2.42 \mathrm{log}$ arc second. Age, best corrected visual acuity, type of refractive error and fusional status had significant association with stereopsis. It is recommended for the tertiary eye care and training center of Gondar University Hospital to incorporate screening of stereopsis in patients with refractive error. Further studies need to be conducted on large scale incorporating robust analytical component to determine the magnitude of poor stereopsis and point out its important predictors.

\section{Disclosure}

The authors have no conflicts of interest to declare.

\section{References}

1. Erkelens CJ. Stability of binocular depth perception with moving head and eyes. Vision Res. 1996;36(23):3827-3842.

2. Levy NS, Glick EB. Stereoscopic perception and Snellen visual acuity. Am J Ophthalmol. 1974;78:722-724.

3. Hrisos S, Clarke MP. Unilateral visual impairment and neurodevelopment performance in preschool children. $\mathrm{Br} J$ Ophthalmol. 2006;90 (7):836-838.

4. Kulp MT, Ying GS. Associations between hyperopia and other vision and refractive error characteristics. OptomVis Sci. 2014;91(4):383.

5. Lee SY, Koo NK. Change of stereo acuity with aging in normal eyes. Korean J Ophthalmol. 2005;19(2):136-139.

6. Shafiee D, Jafari AR, Shafiee AA. Correlation between Inter Pupillary Distance and stereo acuity. Bull Env Pharmacol Life Sci. 2014;3:26-33. 
7. Guo DD, Wu JF. Stereo acuity and related factors: the shandong children eye study. PLoS One. 2016;11(7):157829.

8. Sethi S, Kashyap R. Impact of refractive errors on Stereopsis in school going children of Rural Haryana. Indian J Clin Exp Ophthalmol. 2015;1(2):91-94.

9. Momeni H, Kundart J, Ehasani M, et al. The comparison of stereopsis with TNO and Titmus tests in symptomatic and asymptomatic University students. J Behav Optometry. 2011;23(2):35-39.

10. Garnham L, Sloper JJ. Effect of age on adult stereo acuity as measured by different types of stereo test. Br J Ophthalmol. 2006;90(1):91-95.

11. Gawecki M, Adamski J. Anisometropia and Stereopsis. KlinOczna. 2004;106:5613.

12. Jm R, Kifley A. Prevalence of hyperopia and associations with eye findings in 6-and 12-year-olds. Ophthalmology. 2008;115(4):678-685.

13. Yang JW, Huang TY. Correlation between myopic ametropia and stereo acuity in school-aged children in Taiwan. Jpn J Ophthalmol. 2013;57(3):316-319.

14. Yang JW, Huang TY. The effects of hyperopic and astigmatic ametropia on stereoacuity by Titmus stereo test. Taiwan J Ophthalmol. 2012;2(1):22-24.

15. Campos EC, Enoch JM. Amount of aniseikonia compatible with fine binocular vision: some old and new concepts. J Pediatr Ophthalmol Strabismus. 1980;17(1):44-47.
16. Oguz H, Oguz V. The effects of experimentally induced anisometropia on stereopsis. J Pediatr Ophthalmol Strabismus. 2000;37 (4):214-218.

17. Watanabe H, Okamoto F. Stereopsis after successful surgery for rhegmatogenous retinal detachment. Graefes Arch Clin Exp Ophthalmol. 2014;252(8):1207-1212.

18. Simons K. Preschool vision screening: rationale, methodology and outcome. SurvOpthalmol. 1996;41(1):3.

19. Rico R. The Wiley-Blackwell Handbook of the Psychology of Team Working and Collaborative Processes. John Wiley \& Sons; 2017:1.

20. Venter JC, Adams MD, Myers EW, et al. The sequence of the human genome. science. 2001;291(5507):1304-1351.

21. Lee AG, Martin CO. Neuro-ophthalmic findings in the visual variant of Alzheimer's disease. Ophthalmology. 2004;111 (2):376-380.

22. Levi DM, McKee SP, Movshon JA. Visual deficits in anisometropia. Vision Res. 2011;51(1):48-57.

23. McKee SP, Levi DM, Movshon JA. The pattern of visual deficits in amblyopia. J Vis. 2003;3:5.

24. Faraji M, Kangari H, Majidi A, Tabatabaee SM. Stereopsis in early diabetic retinopathy. Clin Optom (Auckl). 2020;10(12):1-7.
Clinical Optometry

\section{Publish your work in this journal}

Clinical Optometry is an international, peer-reviewed, open access journal publishing original research, basic science, clinical and epidemiological studies, reviews and evaluations on clinical optometry. All aspects of patient care are addressed within the journal as well as the practice of optometry including economic and business analyses. Basic and clinical research papers are published that cover

\section{Dovepress}

all aspects of optics, refraction and its application to the theory and practice of optometry. The manuscript management system is completely online and includes a very quick and fair peer-review system, which is all easy to use. Visit http://www.dovepress.com/ testimonials.php to read real quotes from published authors. 